\title{
Prototipe Layanan VoIP Pada Jaringan OpenFlow
}

\author{
Eki Ahmad Zaki Hamidi, Mufid Ridlo Effendi, Hafizh Wibowo Widodo \\ Jurusan Teknik Elektro UIN Sunan Gunung Djati Bandung \\ Jl. AH. Nasution 105 Bandung - Indonesia \\ e-mail: ekiahmadzaki@uinsgd.ac.id, mufid.ridlo@uinsgd.ac.id, hafizhww@gmail.com.
}

\begin{abstract}
Abstrak - Voice Over Internet Protocol (VoIP) adalah sebuah teknologi yang mampu melewatkan trafik suara dan data yang berbentuk paket melalui jaringan IP. Penggunaan IP memungkinkan penghematan biaya dikarenakan tidak perlu membuat sebuah infrastruktur baru untuk komunikasi suara. Dalam mengaplikasikan VoIP saat ini masih menggunakan infrastruktur jaringan konvensional, dengan berkembangnya SDN (Software Defined Network) yang menawarkan paradigma baru dalam dunia jaringan dalam mendesain, mengelola dan mengimplementasikan jaringan, terutama untuk mendukung kebutuhan dan inovasi di bidang ini yg semakin lama semakin kompleks, maka layanan VoIP dapat diaplikasikan pada jaringan OpenFlow yang merupakan implementasi dari konsep SDN (Software Defined Network). Dalam mengimplementasikan VoIP menggunakan pada jaringan OpenFlow, VoIP dapat dibangun dengan menggunakan aplikasi yang bersifat freeware seperti X-Lite sebagai User Agent atau Client, Asterisk sebagai server VoIP dan G.711 sebagai codec dengan memanfaatkan OpenvSwitch yang berfungsi meneruskan paket-paket dalam layanan VoIP. Pada pengujian ini dilakukan terbagi dalam 2 bagian, pengujian pada OpenvSwitch dan VoIP. Pada pengujian OpenvSwitch dapat disimpulkan bahwa flow yang sudah dibuat pada OpenvSwitch dapat berfungsi untuk meneruskan paketpaket dalam layanan VoIP sehingga antara server dan client dapat terhubung. Pengujian VoIP dilakukan sebanyak 10 kali percobaan dengan hasil yang didapatkan dengan rata-rata delay 10,0002421 ms, throughput 171,195 Kbps, jitter 0,424 ms, packet loss 0\%
\end{abstract}

Kata Kunci: Software Defined Network, OpenFlow, OpenvSwitch, VoIP

\section{Pendahuluan}

VoIP (Voice Over Internet Protocol) adalah sebuah teknologi yang mampu melewatkan trafik suara, video dan data yang berbentuk paket melalui jaringan IP. Penggunaan jaringan IP memungkinkan penghematan biaya dikarenakan tidak perlu membuat infrastruktur baru untuk komunikasi suara dan penggunaan lebar data (bandwith) yang lebih kecil dibandingkan dengan telepon biasa[1][2]. Saat ini ada tiga jenis metode berbeda dan yang paling sering digunakan dalam layanan VoIP yaitu ATA (Analog Telephone Adapter), IP Phones, Computer to Computer[3]. Infrastruktur yang ada saat ini selain menggunakan infrastruktur dengan metode konvenisonal sudah berkembang pula infrastruktur berbasis SDN (Software Defined Network).

SDN erat kaitanya dengan OpenFlow sehingga banyak yang berangapan bahwa SDN adalah OpenFlow. SDN lahir dari protokol OpenFlow yang diusulkan oleh Nick McKeown dan rekanrekanya. OpenFlow adalah spesifikasi komunikasi antara control plane dan data plane OpenFlow merupakan standar terbuka yang diterapkan pada SDN[4][5]. Sebuah switch OpenFlow terdiri dari dua jenis yang pertama adalah hardware-base switch, switch jenis ini telah memodifikasi hardware dengan menggunakan sebuah OS khusus untuk mengimplementasikan OpenFlow protocol dan jenis kedua adalah software base switch yang

TELKA, Vol.4, No.1, Mei 2018, pp. 33 42

ISSN (e): 2540-9123

ISSN (p): 2502-1982 
menggunakan system Unix atau Linux untuk mengimplementasikan seluruh fungsi OpenFlow [6].

Dengan mempertimbangkan fleksibilitas SDN (Software Defined Network) berbasis OpenFlow yang memungkinkan dapat diimplementasikan pada layanan VoIP (Voice Over Internet Protocol).

\section{Metodologi Penelitian}

Penelitian ini memiliki beberapa dengan tahapan. Tahap-tahap tersebut dipersiapkan untuk menunjang proses penelitian agar berjalan sistematis. Dari beberapa tahapan, kemudian disusun dalam bentuk diagram atau flowchart seperti berikut:

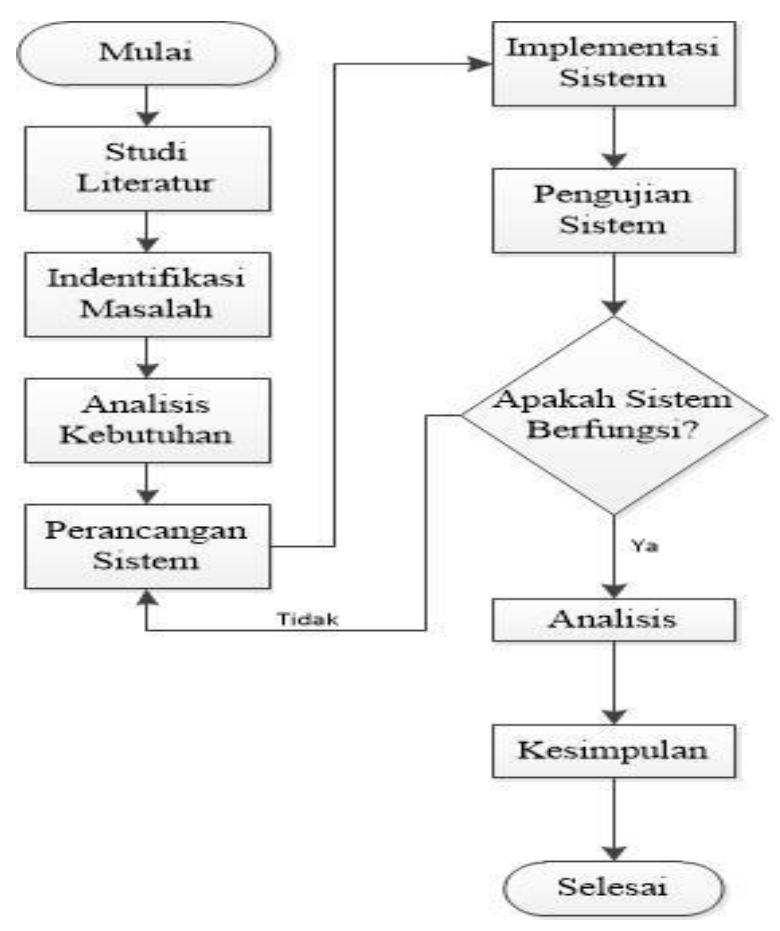

Gambar 1. Flowchart Metodologi Penelitian

\section{Rancangan dan Implementasi}

Perancangan yang digunakan adalah perancangan server VoIP mengguunakan software Asterisk dengan Ubuntu 16.04 sebagai sistem operasinya. Selanjutnya untuk client VoIP menggunakan X-lite Softphone sehingga mampu melakukan penerimaan panggilan dengan sesama client yang sudah terdaftar pada server VoIP. Dan untuk mengimplementasikan layanan VoIP pada jaringan OpenFlow maka digunakan OpenvSwitch sebagai switch virtual OpenFlow dengan sistem operasi Linux Debian 8 dengan tambahan network interface card (NIC) yang berfungsi sebagai penghubung antara server dan client, kemudian dilakukan analisis pengujian dengan menggunakan software wireshark dengan parameter pengujian berupa delay, jitter, packet loss dan throughput. 


\subsection{Topologi Jaringan}

Topologi yang digunakan adalah:

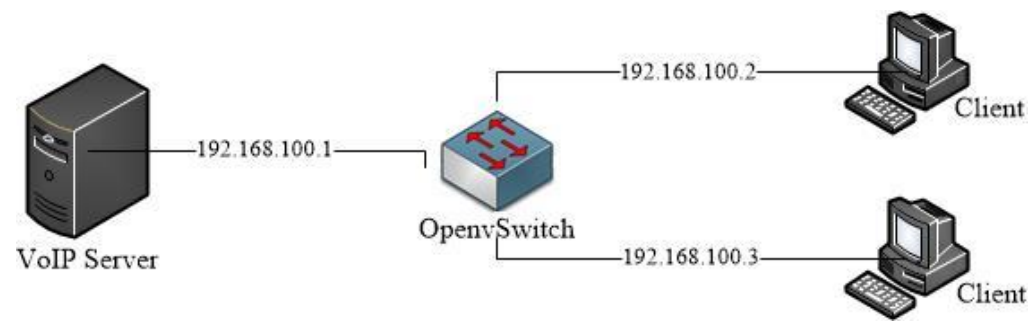

Gambar 2. Topologi Jaringan

\subsection{Konfigurasi Asterik}

Sebagian besar konfigurasi Asterisk terletak di direktori /etc/asterisk. File SIP.conf berisi parameter yang berkaitan dengan konfigurasi SIP untuk server Asterisk, dengan memberikan perintah "nano /etc/asterisk/sip.conf" yang berfungsi untuk membuat sebuah penomoran serta password pada client yang akan digunakan sehingga memungkinkan client dapat berkomunikasi dengan client lainya.

Setelah proses konfigurasi pada file SIP.conf tahap selanjutnya adalah dengan melakukan konfigurasi pada file extensions.conf yang berfungsi untuk membuat pola panggilan yang akan dilakukan dengan menggunakan perintah "nano /etc/asterisk/extensions.conf"

\subsection{Konfigurasi Softphone}

Beberapa konfigurasi sistem yang bertujuan agar sesama client yang telah terdaftar pada server VoIP dapat menerima dan melakukan panggilan.

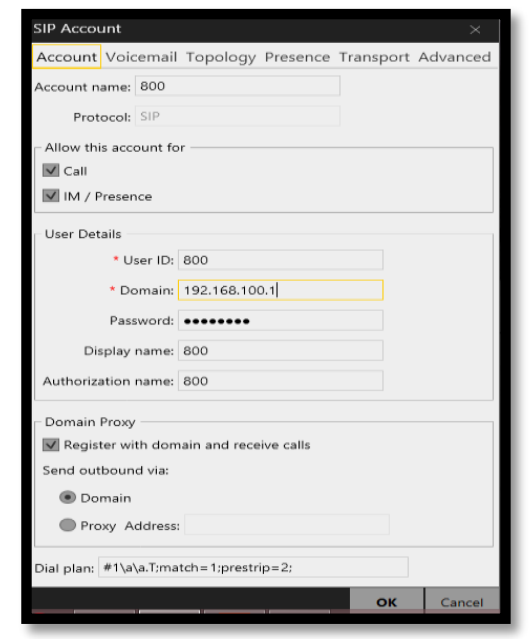

Gambar 3. Konfigurasi Softphone

Dalam proses membuat akun yang sudah sesuai nama, nomor dan password maka akan secara otomatis softphone VoIP akan mendeteksi terhadap perubahan-perubahan parameter (syarat sudah terhubung dalam satu jaringan). Apabila tahap konfigurasi sudah tidak terdapat masalah maka akan terlihat softphone atau client VoIP yang sudah siap digunakan dalam menerima atau melakukan panggilan, dapat dilihat pada gambar 4 berikut dibawah ini: 


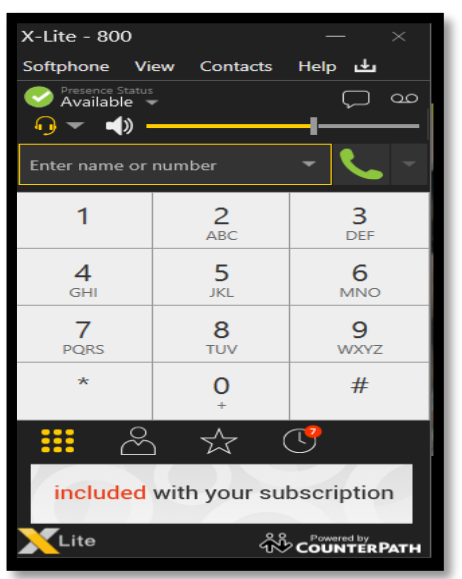

\subsection{OpenvSwitch}

Gambar 4. Softphone

Switch berfungsi sebagai manajemen lalu lintas yang terdapat pada jaringan komputer, dan switch juga bertugas sebagai media untuk mengirimkan sebuah paket data untuk sampai ke tujuan dengan mencari jalur yang paling baik dan optimal serta memastikan pengiriman paket data ke tujuanya. Switch tersebut difungsikan sebagai OpenvSwitch atau switch virtual OpenFlow dan switch TP-link T1-SF11008D.

\section{Hasil dan Analisa}

Beberapa skenario analisa pada VoIP dengan tujuan mendapatkan sebuah hasil perbandingan antara penggunaan layanan VoIP menggunakan switch OpenFlow dan menggunakan switch TP-Link T1-SF1008D dan kemudian diambil nilai rata-rata dari setiap pengukuran.

\subsection{Analisa Panggilan VoIP pada Switch OpenFlow}

Proses pertama pada OpenvSwitch yang dilakukan adalah dengan up-port yang bertujuan agar port dalam switch virtual dalam keadaan aktif (Up) dan siap digunakan.

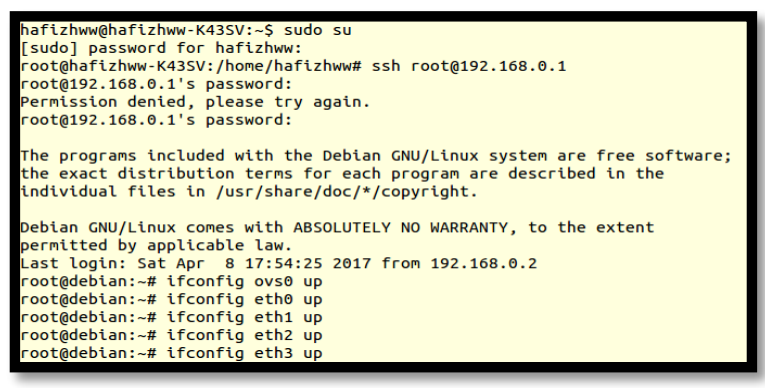

Gambar 5. Up Port OpenvSwitch

Proses yang kedua adalah dengan membuat flow pada OpenvSwitch dengan perintah ovsofctl add-flow ovs0 


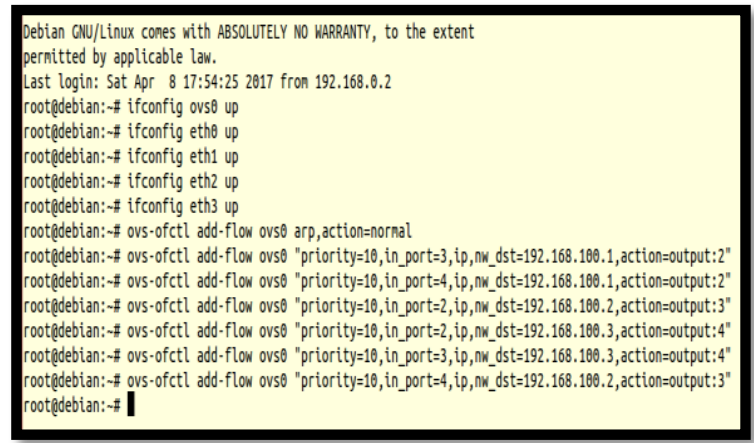

Gambar 6. Proses Add-flow OpenvSwitch

Proses selanjutnya adalah dengan melakukan dump-flow berfungsi untuk melihat paket yang digunakan, dan yang menjadi acuan pada dump-flow ini adalah n_packet dijadikan salah satu acuan yang dilihat karena n_packet muncul beberapa kali paket itu digunakan, pada pengujian ini $n \_$packet yang didapat tidak 0 artinya flow sering digunakan.

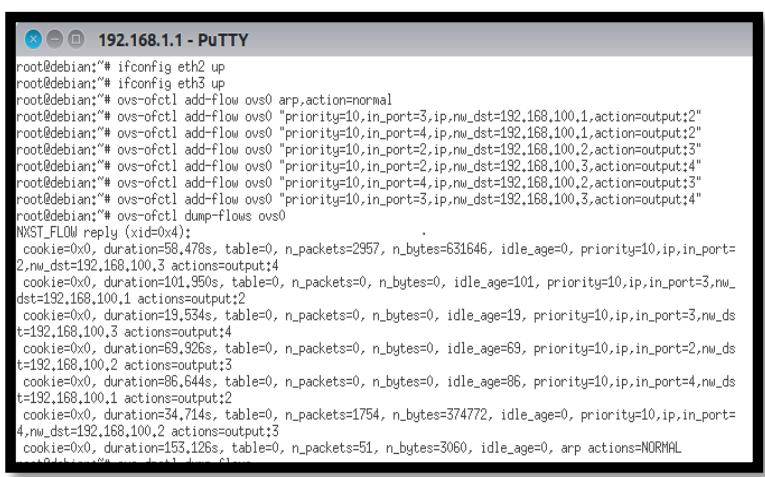

Gambar 7. Proses Dump-flow OpenvSwitch

Proses add-flow pada OpenvSwitch sudah dilakukan maka proses selanjutnya adalah dengan memastikan bahwa koneksi jaringan pada server VoIP melalui OpenvSwitch terhadap client satu dan dua sudah terhubung dengan baik. Pengujian dilakukan dengan "ping" pada terminal dengan perintah "ping 192.168.100.2" untuk client satu dan "ping 192.168.100.3" untuk client dua.

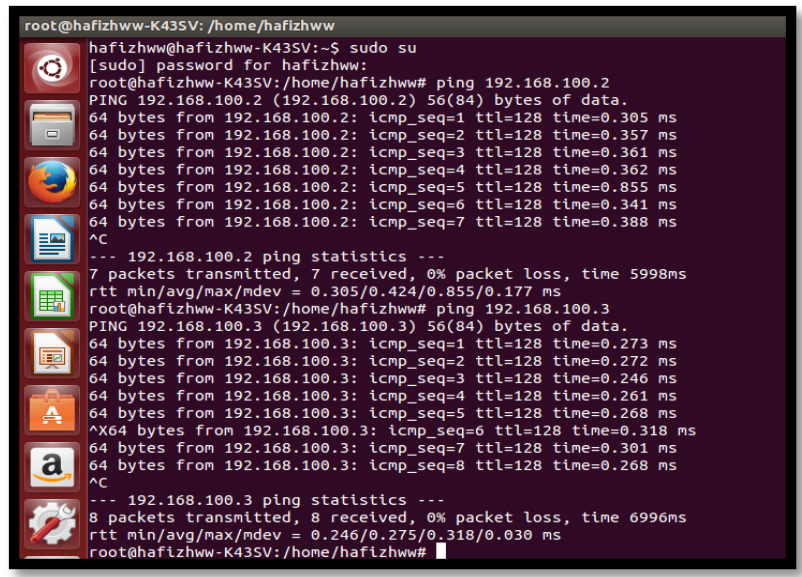

Gambar 8. Cek Konektifitas 
Dalam melakukan panggilan dalam VoIP setiap client harus sudah terdaftar pada server VoIP. Proses panggilan ini sangat mirip dengan komunikasi yang biasa dilakukan pada handphone, untuk melihat client VoIP yang aktif pada server adalah dengan memberikan perintah pada asterisk $-\mathrm{r}$ sip show peers.

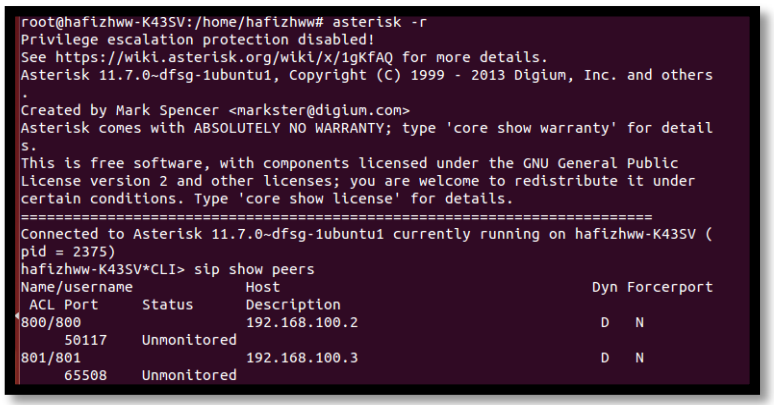

Gambar 9. Client VoIP sudah terdaftar pada server

Setelah akun client satu VoIP dengan nomor dial 800 dan akun client dua dengan nomor dial 801 sudah terdaftar pada server maka client VoIP dapat melakukan panggilan. Dengan menekan nomor dial yang sudah teregistrasi pada server, seperti pada gambar berikut ini:

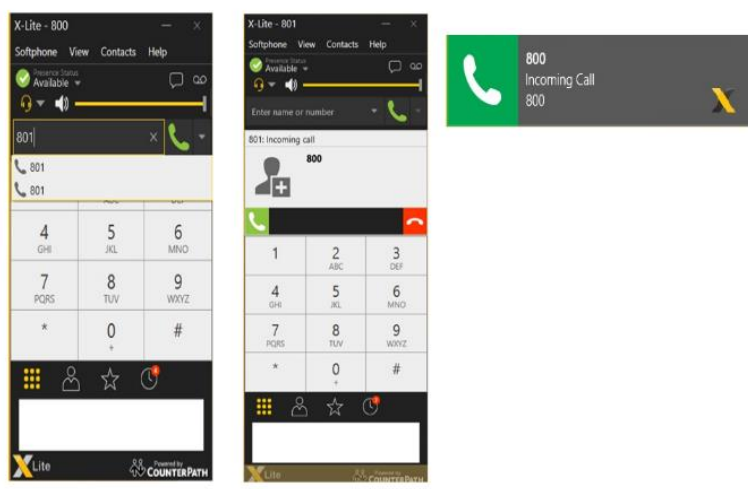

Gambar 10. Client VoIP sudah terdaftar pada server

Pada gambar diatas adalah kondisi dimana client satu dengan nomor dial 800 akan melakukan panggilan dengan client dua yang mempunyai nomor dial 801. Pada proses tunggu ini, client dua terdapat tanda incoming call dari client satu yang sedang menunggu apakah permintaan call diterima atau ditolak. Pilih logo telepon untuk menerima komunikasi.
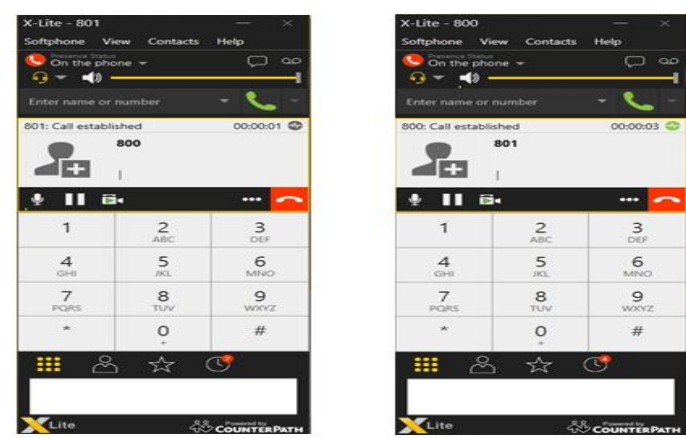

Gambar 11. Client VoIP on the phone 
Apabila proses komunikasi berjalan (client dua menjawab telepon), maka informasi yang terdapat pada status softphone client satu dan dua berubah menjadi seperti gambar 5.8 diatas, informasi "on the phone" tersebut menandakan bahwa client satu dan client dua sedang beroprasi melakukan komunikasi.

\subsection{Analisa Quality of Service}

Adalah kemampuan suatu jaringan untuk menyediakan kemampuan suatu jaringan untuk menyediakan layanan yang lebih baik pada trafik tertentu pada berbagai jenis platform teknologi. Dan pada hasil penelitian VoIP yang didapat akan dibandingkan dengan rekomendasi ITU-T dan TIPHON mengenai standar kualitas layanan VoIP seperti dibawah ini :

a. Delay (harus $\leq 150 \mathrm{~ms}$, ITU-T G.114)

b. Jitter (harus $\leq 75 \mathrm{~ms}$, TIPHON)

c. Packet Loss (harus $\leq 5 \%$, ITU-T G.114)

d. Throughput

Pengukuran dilakukan dengan penggunaan variasi switch yang digunakan. Switch yang digunakan untuk pengukuran adalah switch virtual OpenFlow (OpenvSwitch) dan switch TPLink T1-SF1008D. pengambilan data dilakukan sebanyak 10 kali panggilan dengan waktu sekali panggilan adalah 5 menit. Pengukuran dilakukan dengan software wireshark dengan codec G.711.

\subsubsection{Analisa Delay}

Delay langsung berhubungan dengan kecepatan transfer data suatu jaringan, delay sangat berpengaruh terhadap data real-time seperti data suara pada aplikasi VoIP. Semakin besar nilai delay maka semakin buruk juga kualitas jaringan serta kualitas data yang diterima oleh pendengar [19]:

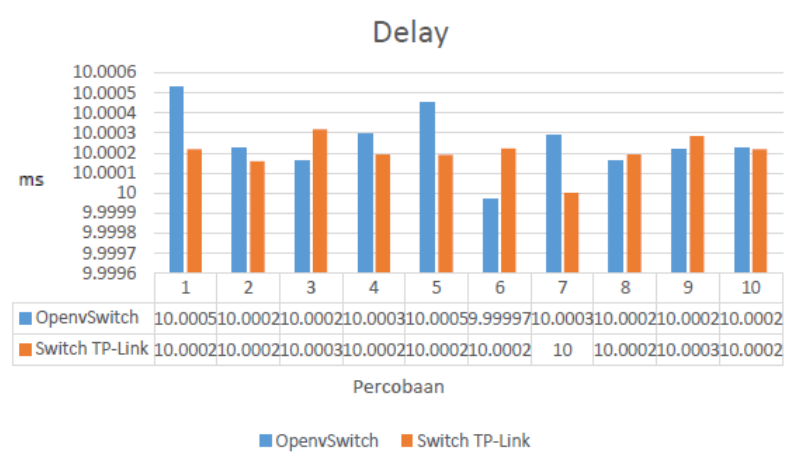

Gambar 12. Grafik Perbandingan Nilai Delay VoIP

Pada proses pengukuran delay pada komunikasi VoIP dengan menggunakan OpenvSwitch mempunyai nilai rata-rata delay sebesar $10.0002421 \mathrm{~ms}$, sedangkan menggunakan switch TPLink mempunyai nilai rata-rata delay sebesar 10,000989 ms. Dari hasil pengukuran kualitas suara pada layanan VoIP yang diterapkan OpenvSwitch dan pada switch TP-Link masih dianggap baik, dikarenakan menurut rekomendasi dari ITU-T dan TIPHON nilai delay yang disarankan adalah kurang dari $150 \mathrm{~ms}$.

Dari hasil pengukuran besar nilai delay pada penelitian ini dipengaruhi oleh besar nilai throughput. Nilai throughput berbanding terbalik dengan nilai delay, semakin besar nilai throughput maka semakin kecil delay yang dihasilkan. 


\subsubsection{Data Throughput}

Pengukuran throughput dilakukan untuk mengetahui laju data dalam suatu panggilan, sehingga bisa direkomendasikan persyaratan pada bandwith minimal yang akan digunakan.

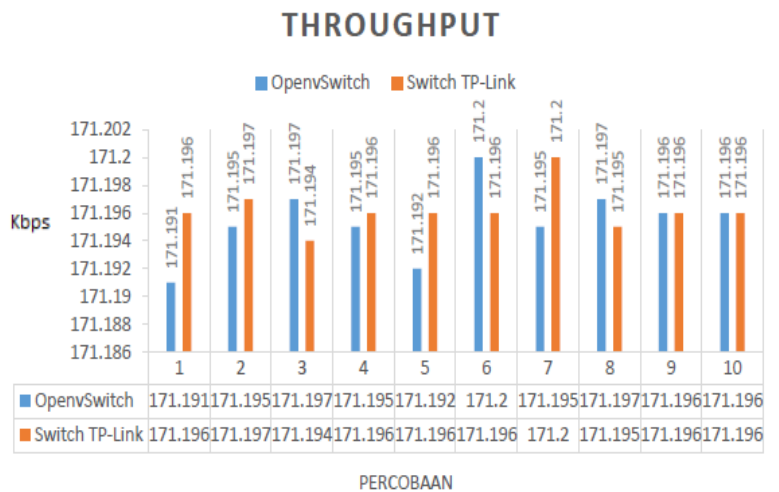

Gambar 13. Grafik Perbandingan Nilai Throughput VoIP

Pada pengukuran throughput dengan semakin lamanya durasi berbicara dengan menggunakan layanan VoIP, maka nilai delay yang ditimbulkan semakin besar, hal ini mempengaruhi nilai dari sebuah throughput. Dikarenakan pada pengujian ini dibatasi waktu pembicaraanya selama kurang lebih 5 menit, sehingga nilai rata-rata throughput pada OpenvSwitch sebesar 171,195 kbps, sedangkan menggunakan switch TP-Link mempunyai nilai rata-rata throughtput sebesar 171,196 ms. Dikarenakan pada percobaan ini hanya menggunakan dua client dan masih berada pada jaringan lokal dan menggunakan media kabel sehingga nilai yang didapatkan pada penelitian ini relatif sama.

\subsubsection{Analisa Jitter}

Jitter merupakan sebuah variasi delay antar paket yang terjadi pada jaringan IP, besarnya nilai jitter dipengaruhi oleh variasi beban trafik dan besarnya penumpukan antar paket yang ada dalam jaringan IP [19].

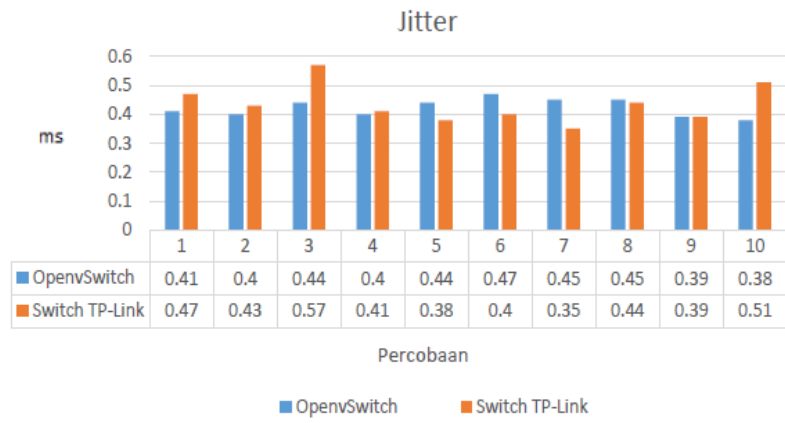

Gambar 14. Grafik Perbandingan Nilai Jitter VoIP

\subsubsection{Analisa Packet Loss}

Packet Loss adalah hilangnya satu atau lebih paket data yang berjalan pada jaringan atau dengan kata lain paket data yang gagal dalam mencapai tujuan [19]. 


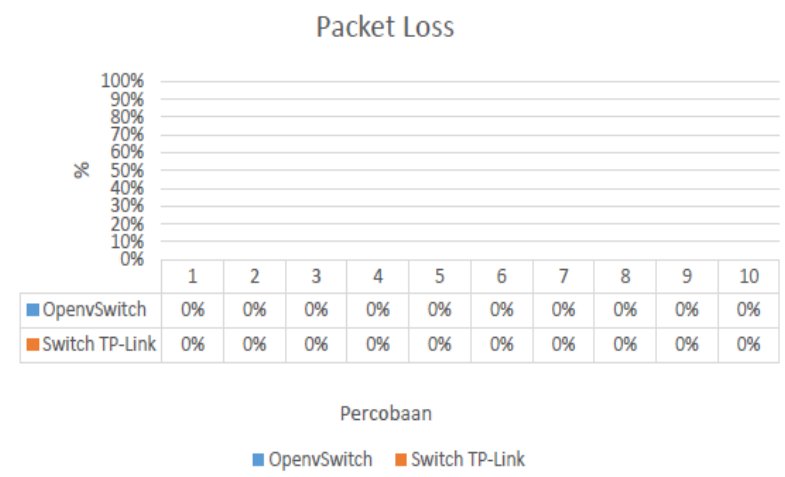

Gambar 15. Grafik Perbandingan Nilai Packet Loss VoIP

Berdasarkan hasil pengukuran pada layanan VoIP dengan menggunakan OpenvSwitch dan switch TP-Link didapatkan hasil rata-rata adalah $0 \%$ maka dari itu dapat dikategorikan adalah kondisi sangat bagus, karena pada standarisasi TIPHON mengkategorikan bahwa kualitas jaringan dengan nilai $0 \%$ adalah sangat bagus.

Berdasarkan pada hasil pengujian layanan VoIP (Voice Over Internet Protocol) yang sudah ditampilkan dalam bentuk grafik yang dilakukan dengan menggunakan OpenvSwitch dan switch TP-Link dengan beberapa skenario pengujian.

Dapat disimpulkan dengan menganalisa data-data yang dihasilkan oleh software wireshark tersebut, dari hasil pengujian yang sudah dilakukan dapat dilihat pada tabel berikut ini.

Tabel 1. Analisa Performansi Jaringan

\begin{tabular}{|c|c|c|}
\hline Quality of Service & OpenvSwitch & Switch TP-Link \\
\hline Delay & $10,0002421 \mathrm{~ms}$ & $10,0001989 \mathrm{~ms}$ \\
\hline Throughput & $171,195 \mathrm{Kbps}$ & $171,196 \mathrm{Kbps}$ \\
\hline Jitter & $0,424 \mathrm{~ms}$ & $0,435 \mathrm{~ms}$ \\
\hline Packet Loss & $0 \%$ & $0 \%$ \\
\hline
\end{tabular}

\section{Kesimpulan}

Kesimpulan Implementasi VoIP pada jaringan OpenFlow dengan menggunakan OpenvSwitch sebagai switch virtual OpenFlow. Dan sudah dilakukan sebuah pengukuran QoS terhadap sesi komunikasi dengan menggunakan SIP (Session Innitiation Protocol) untuk signaling, protokol RTP (Real-Time Protocol) untuk transport dan Codec audio G.711 maka dapat disimpulkan dari perancangan, implementasi dan pengujian sistem ini di dapat hasil sebagai berikut:

1. VoIP pada jaringan OpenFlow berhasil diimplementasikan.

2. Penggunaan priority pada OpenvSwitch pada pengujian ini tidak terlalu berpengaruh dikarenakan jaringan yang digunakan adalah skala kecil, namun pada skala besar akan berpengaruh.

3. Port service VoIP yang digunakan pada OpenvSwitch adalah random.

4. Pengujian VoIP dilakukan sebanyak 10 kali percobaan dengan hasil yang didapatkan dengan rata-rata delay $10,0002421 \mathrm{~ms}$, throughput $171,195 \mathrm{Kbps}$, jitter 0,424 ms, packet loss $0 \%$. 


\section{Daftar Pustaka}

[1] Lazuardi, N., 2009. Perencanaan Jaringan Komunikasi VoIP (Voice Over Internet Protokol) Menggunakan Asterisk SIP (Session Initiation Protocol).

[2] Yuniati, Y., Fitriawan, H. and Patih, D.F.J., 2014. Analisa Perancangan Server VoIP (Voice Internet Protocol) dengan Opensource Asterisk dan VPN (Virtual Private Network) Sebagai Pengaman Jaringan Antar Client. Jurnal Sains dan Teknologi Industri, 12(1), pp.112-121.

[3] Wahyuddin, M.I., 2009. Implementasi VoIP Computer To Computer Berbasis Freeware Menggunakan Session Initiation Protocol. , 3(1), pp.50-59.

[4] Kartadie, R. and Satya, B., 2015. Uji Performa Implementasi Software-Based OpenFlow Switch Berbasis OpenWRT Pada Infrastruktur Software-Defined Network. DASI, 16(3), p.87.

[5] Cui, Hongyan, et al. "Accurate Network Resource Allocation in SDN according to Traffic Demand." (2015). openflow halaman 26

[6] Kartadie, R., Utami, E. and Pramono, E., 2014. Prototipe Infrastruktur Software-Defined Network Dengan Protokol OpenFlow Menggunakan UBUNTU Sebagai Kontroler. DASI, 15(1), p.24.

[7] Gojali, I., 2013. Modul Jaringan Komputer.

[8] Salwa, M.I., 2016. Implementasi DHCP server multi subnet menggunakan switch OpenFlow. Universitas Islam Negeri Sunan Gunung Djati Bandung.

[9] Mahardwiani, I., 2015. Desain dan implementasi telepon internet pada jaringan komputer Laboratorium Telekomunikasi Politeknik Negeri Bandung. Politeknik Negeri Bandung.

[10] Ilma, U.Z., 2011. Rancang bangun dan analisa Quality of service (QoS) pada sistem Voice Over Internet Protocol (VoIP) menggunakan opensource Elastix. Institut Sains dan Teknologi Nasional.

[11] Supriyanto, 2013. Jaringan Dasar 1. Available at: https://docs.google.com

[12] Syamsu, S.,Modul Jaringan Komputer. Stimik AKBA

[13] Li, Y., \& Wang, G. (2013). SDN-based switch implementation on network processors. Communications and Network, 5(03), 434.

[14] Tulloh, R., Negara, R.M. and Hidayat, A.N., 2015. Simulasi Virtual Local Area Network (VLAN) Berbasis Software Defined Network (SDN) Menggunakan POX Controller. JURNAL INFOTEL, 7(2), pp.129-136.

[15] Baek, Sun Uk, et al. "Implementation and Verification of QoS Priority over Software Defined Networking." Proceedings on the International Conference on Internet Computing (ICOMP). The Steering Committee of The World Congress in Computer Science, Computer Engineering and Applied Computing (WorldComp), 2016

[16] ONF Market Education Committee, 2012. Software-defined networking: The new norm for networks. ONF White Paper.

[17] Risdianto, A.C., Arif, M. \& Mulyana, E., 2013. Buku Komunitas SDN-RG: Pengantar SDN

[18] Thorpe, Christina, et al."iMOS: Enabling VoIP QoS Monitoring at Intermediate Nodes in an OpenFlow SDN." Cloud Engineering Workshop (IC2EW), 2016 IEEE International Conference on. IEEE, 2016.

[19] Ketut Sudiarta, P. and Sukadarmika, G., 2012. Penerapan Teknologi VoIP Untuk Mengoptimalkan Penggunaan Jaringan Intranet Kampus Universitas Udayana. Majalah Ilmiah Teknologi Elektro, 8(2). 